\title{
La Encíclica Sollicitudo rei socialis y la preocupación de Juan Pablo II por el desarrollo de los pueblos. Reflexión en el 25 aniversario de la encíclica Sollicitudo rei socialis
}

\author{
The Encyclical Sollicitudo rei socialis and John Paul II's Concern for \\ the Development of the Nations. A reflection on the $25^{\text {th }}$ anniversary \\ of writing the Encyclical Sollicitudo rei socialis
}

\section{Abstract}

The Catholic Church's teaching on the development of the nations is generally included in two documents: Populorum Progressio by Pope Paul VI and Sollicitudo rei socialis by John Paul II. This year marks the $25^{\text {th }}$ anniversary of publishing the Encyclical Sollicitudo rei socialis, hence the motive for writing this article. A characteristic feature of the teaching of John Paul II, which we find in this Encyclical, is the ethical dimension of development. The Pope repeatedly drew attention to the inequitable distribution of material goods in the world. He stressed that "True development, in keeping with the specific needs of the human being - man or woman, child, adult or old person implies, especially for those who actively share in this process and are responsible for it, a lively awareness of the value of the rights of all and of each person. It likewise implies a lively awareness of the need to respect the right of every individual to the full use of the benefits offered by science and technology" Sollicitudo rei socialis 33. This article consists of the four following issues: 1. Populorum Progressio and a new analysis on the development of the nations; 2 . The main motive for the publication of Sollicitudo rei socialis; 3. The concept of development in the teaching of John Paul II; 4. Topicality of the papal document -25 years later. 


\section{Keywords}

John Paul II, Populorum progressio, development, solidarity, Sollicitudo rei socialis, poverty.

La enseñanza de la Iglesia acerca del desarrollo de los pueblos está contenida principalmente en las Cartas encíclicas Populorum progression de Pablo VI y Sollicitudo rei socialis de Juan Pablo II, publicadas en los años 1967 y 1987 respectivamente.

La encíclica Sollicitudo rei socialis esboza un panorama del mundo contemporáneo. Leer hoy día esta parte nos lleva a pensar que las reflexiones ofrecidas en 1987 contienen numerosos elementos que siguen siendo válidos para comprender la situación que vivimos actualmente, como en Europa y en otras partes del mundo, después de la caída del bloque comunista, cuando se produjeron cambios políticos de gran trascendencia. La esperanza de desarrollo presentada en la Populorum progressio, estaba muy lejos de ser realidad en 1987 (podemos añadir, también hoy), por la miseria en la que vivían (y viven) millones de seres humanos $^{1}$. Juan Pablo II incluso señaló cómo se había llegado a una acentuación del subdesarrollo, motivada por muchos factores que llevaron a que los países ricos fuesen más ricos y los más pobres siguiesen en situaciones intolerables de miseria, agravadas por problemas como los originados por culpa de la deuda externa ${ }^{2}$.

En el documento Juan Pablo II busca profundizar en la auténtica noción de desarrollo, una noción más rica y completa que la idea de progreso elaborada en el contexto del Iluminismo occidental. Cuando se acumulan bienes y recursos sin un objetivo moral, es posible que tal acumulación se vuelva contra el mismo hombre, lo cual lleva a producir más daños que beneficios ${ }^{3}$.

La encíclica de Benedicto XVI, Spe salvi, subraya esta misma idea, al criticar la idea de "progreso” elaborada en los últimos siglos, y al recordar que la “ciencia puede contribuir mucho a la humanización del mundo y de la humanidad. Pero también puede destruir al hombre y al mundo si no está orientada por fuerzas externas a ella misma"4.

Un desarrollo solamente económico no es capaz de liberar al hombre, al contrario, lo esclaviza todavía más. El ser humano es totalmente libre sólo cuando

\footnotetext{
${ }^{1}$ Cfr. Juan Pablo II, Encíclica Sollicitudo rei socialis, 12-19.

${ }^{2}$ Cfr, Ibídem, 19.

${ }^{3}$ Cfr, Ibídem, 28.

${ }^{4}$ Cfr. Benedicto XVI, Encíclica Spe salvi, 25.
} 
es él mismo, en la plenitud de sus derechos y deberes; y lo mismo cabe decir de toda la sociedad.

La libertad con la cual Cristo nos ha liberado nos mueve a convertirnos en siervos de todos. De esta manera el proceso del desarrollo y de la liberación se resume en el ejercicio de la solidaridad, es decir, del amor y servicio a los demás, particularmente a los más pobres. Porque donde faltan la verdad y el amor, el proceso de liberación lleva a la muerte de una libertad que habría perdido todo apoyo.

La Iglesia también tiene confianza en el hombre, aun conociendo la maldad de que es capaz, porque sabe bien, si el hombre fue creado a imagen y semejanza de Dios el hombre debe seguir sus pasos y tratar de hacerlo lo mejor posible. Por tanto, no se justifican ni la desesperación, ni el pesimismo, ni la pasividad. Aunque conviene decir que, así como se puede pecar por egoísmo, por afán de ganancia exagerada y de poder, se puede faltar también ante las urgentes necesidades de unas muchedumbres hundidas en el subdesarrollo por temor, indecisión y, en el fondo, por cobardía. Todos estamos llamados, más aún obligados, a afrontar este tremendo desafío de los últimos años. Y ello, porque unos peligros ineludibles nos amenazan a todos: una crisis económica mundial, una guerra sin fronteras, sin vencedores ni vencidos. Ante semejante amenaza, la distinción entre personas y países ricos, entre personas y países pobres, contará poco, salvo por la mayor responsabilidad de los que tienen más y pueden más. Lo que está en juego es la dignidad de la persona humana, cuya defensa y promoción nos han sido confiadas por el Creador, y de las que son rigurosa y responsablemente deudores los hombres y mujeres en cada época de la historia. El panorama actual, no parece responder a esta dignidad. Cada uno está llamado a ocupar su propio lugar en esta campaña pacífica que hay que realizar con medios pacíficos para conseguir el desarrollo en la paz, para salvaguardar la misma naturaleza y el mundo que nos rodea. También la Iglesia se siente profundamente implicada en este camino del desarrollo, en cuyo éxito final espera. Precisamente éste es el motivo principal del presente artículo, es decir, recordar la enseñanza del papa Juan Pablo II en materia del desarrollo. El tema está dividido en cuatro puntos: 1. Populorum progressio y un nuevo análisis sobre el desarrollo de los pueblos; 2. Motivo de la publicación de la Sollicitudo rei socialis; 3. Pensamiento de Juan Pablo II sobre el concepto de desarrollo; 4.25 años después - actualidad del documento papal. 


\section{Populorum progressio y un nuevo análisis sobre el desarrollo de los pueblos}

Los eventos de naturalza económica que se produjeron en el siglo XIX tuvieron consecuencias sciales, políticas y culturales devastadoras. Los acontecimientos vinculados a la revolución industrial transtornaron estructuras sociales seculares, ocasionando al mismo tiempo graves problemas de justicia y dando lugar a la primera gran cuestión social, la cuestión obrera causada por el conflicto entre capital y trabajo. Como respuesta a esta cuestión social, Leon XIII promulga la primera encíclica social, la Rerum novarum. Este documento enumera los errores que provocaron el mal social. El tema central de la encíclica es la instauración de un orden social justo, en visto del cual se deben identficar los criterios de juicio que ayuden a valorar los ordenamientos socio-políticos existentes ${ }^{5}$.

El papa Pablo VI afirma que la Iglesia está atenta a la problemática del desarrollo pleno, y no principalmente a un enfoque de aumento de la renta: "El desarrollo de los pueblos y muy especialmente el de aquellos que se esfuerzan por escapar del hambre, de la miseria, de las enfermedades endémicas, de la ignorancia; que buscan una más amplia participación en los frutos de la civilización, una valoración más activa de sus cualidades humanas; que se orientan con decisión hacia el pleno desarrollo; es observado por la Iglesia con atención”6. Desde casi el principio de la encíclica, el papa caracteriza su visión: "Por esto hoy dirigimos este solemne llamamiento para una acción concreta a favor del desarrollo integral del hombre y del desarrollo solidario de la humanidad"7. Después, se propone la finalidad de la actividad y de la disciplina económica: "La economía está al servicio del hombre"». Coherentemente, señala que en esa perspectiva se dan los sueños y anhelos devastos sectores de la humanidad: "Verse libres de la miseria, hallar con más seguridad la propia subsistencia, la salud, una ocupación estable; participar todavía más en las responsabilidades, fuera de toda opresión y al abrigo de situaciones que ofendan su dignidad de hombres; ser más instruidos; en una palabra, hacer, conocer y tener más para ser más: tal es la aspiración de los hombres de hoy, mientras que un gran número de ellos se ven condenados a vivir en condiciones que hacen ilusorio este legítimo deseo”. La múltiple actividad

\footnotetext{
${ }^{5}$ Cfr. Pontificio Consejo Justicia y paz, Compendio de la doctrina social de la Iglesia, Madrid 2005, p. 44-45.

${ }^{6}$ Pablo VI, Encíclica Populorum progressio, 1.

${ }^{7}$ Ibídem, 5.

${ }^{8}$ Ibídem, 26.

${ }^{9}$ Ibídem, 6 .
} 
humana, el actuar y el conocer, así como el genuino deseo de poseer, se han de orientar a la realización de las personas, como a su fin. En efecto, todo parece indicar, hoy como hace 45 años, que "el tener más, lo mismo para los pueblos que para las personas, no es el fin último" 10 .

Veinte años después de la Populorum progressio Juan Pablo II hace un nuevo análisis sobre el desarrollo de los pueblos: „Convencido de que las enseñanzas de la Encíclica Populorum Progressio, dirigidas a los hombres y a la sociedad de la década de los sesenta, conservan toda su fuerza de llamado a la conciencia, ahora, en la recta final de los ochenta, en un esfuerzo por trazar las líneas maestras del mundo actual, - siempre bajo la óptica del motivo inspirador, «el desarrollo de los pueblos», bien lejos todavía de haberse alcanzado - me propongo prolongar su eco, uniéndolo con las posibles aplicaciones al actual momento histórico, tan dramático como el de hace veinte años"11.

El objetivo del documento papal es subrayar las investigaciones teológicas sobre las realidades contemporáneas, la necesiadad de una concepción diferenciada del desarrollo de los pueblos. Juan Pablo II se refiere a la Populorum progressio como una respuesta a la llamada a la solidaridad. Las acciones de cada hombre tienen su relación no sólo con aquellos que le son inmediatos, sino que las consequencias de sus actos se ligan a la totalidad de la humanidad. El papa lo expresa en las siguientes palabras: „,consiguiente, los responsables de la gestión pública, los ciudadanos de los países ricos, individualmente considerados, especialmente si son cristianos, tienen la obligación moral - según el correspodiente grado de responsabilidad - de tomar en consideración, en las decisiones personales y de gobierno, esta relación de universalidad, esta interdependencia que subsiste entre su forma de comportarse y la miseria y el subdesarrollo de tantos miles de hombres"12.

„El desarrollo es el nuevo nombre de paz”, así afirma Pablo VI en la encíclica Populorum progressio, que puede ser considerada una ampliación del capítulo sobre la vida económico-social de la Gaudium et spes, no obstante introduzca algunas novedades significativas. A partir de esta frase Juan Pablo II concluye que esta expresión es una invitación a revisar el concepto de desarrollo. No se resume éste en una mera acumulación de bienes, sino que implica necesariamente el respeto a la justicia como camino a la instauración de la paz. En este contexto Juan Pablo II escribe: „¿Cómo justificar el hecho de que grandes cantidades de dinero, que podrían y deberían destinarse a incrementar el desarrollo de los

\footnotetext{
${ }^{10}$ Ibídem, 19.

${ }^{11}$ Sollicitudo rei socialis, 4

${ }^{12}$ Ibídem, 9.
} 


\section{2

pueblos, son, por el contrario utilizados para el enriquecimiento de individuos o grupos, o bien asignadas al aumento de arsenales, tanto en los Países desarrollados como en aquellos en vías de desarrollo, trastocando de este modo las verdaderas prioridades? Esto es aún más grave vistas las dificultades que a menudo obstaculizan el paso directo de los capitales destinados a ayudar a los Países necesitados. Si «el desarrollo es el nuevo nombre de la paz», la guerra y los preparativos militares son el mayor enemigo del desarrollo integral de los pueblos"13.

\section{Motivo de la publicación de la Sollicitudo rei socialis}

El studio que Juan Pablo II realiza en la encíclica Sollicitudo rei socialis presenta una estructura metodológica basada en la detección de los problemas y la búsqueda de su etiología, terminando con un apunte de esperanza al señalar los aspectos positivos de las modificaciones sufridas por la sociedad de los veinte años transcurridos desde la publicación de la encíclica Populorum progressio ${ }^{14}$.

La relación de los problemas comienza con una denuncia del peligro de una ruptura de la unidad del género humano, seriamente amenazada y latente en la propia terminología utilizada para designar la situación de desarrollo de los distintos países: primer mundo, segundo mundo, tercer mundo y cuarto mundo, basada en separaciones que tienen su explicación en los niveles de adelanto tecnológico. Para Juan Pablo II, constituyendo una auténtica maldad la realidad de estas distancias que califica de abismales, lo que se presenta como más preocupante es la dinámica de su evolución, es decir, no se acercan los países pobres a los ricos, sino que cada día se produce un mayor alejamiento en la comparación de sus particulares desarrollos. „La palabra «abismo» vuelve a los labios espontáneamente. Tal vez no es éste el vocablo adecuado para indicar la verdadera realidad, ya que puede dar la impresión de un fenómeno estacionario. Sin embargo, no es así. En el camino de los países desarrollados y en vías de desarrollo se ha verificado a lo largo de estos años una velocidad diversa de aceleración, que impulsa a aumentar las distancias. Así los países en vías de desarrollo, especialmente los más pobres, se encuentran en una situación de gravísimo retraso”"15.

\footnotetext{
${ }^{13}$ Ibídem, 10.

${ }^{14}$ Cfr. M. Castillejo Gorraiz, Comentarios a las encíclicas sociales de Juan Pablo II, Córdoba 1995, p. 33.

${ }^{15}$ Sollicitudo rei socialis, 14.
} 
Juan Pablo II continúa la denuncia señalando los mecanismos económicos, financieros y sociales para resolver las desigualdades, ya que, en su criterio, más bien propician un incremento de las mismas: „es necesario denunciar la existencia de unos mecanismos económicos, financieros y sociales, los cuales, aunque manejados por la voluntad de los hombres, funcionan de modo casi automático, haciendo más rígida las situaciones de riqueza de los unos y de pobreza de los otros ${ }^{\prime 16}$.

A este panorama responde el papa polaco con una rspuesta contundente. Piensa que hay que cambiar el sentido actual del concepto, convirtiendo para ello el desarrollo en un hecho común a la totalidad del mundo: „Precisamente dentro de estos Países se encuentran, aunque en menor medida, las manifestaciones más específicas del subdesarrollo. De suerte que debería ser una cosa sabida que el desarrollo o se convierte en un hecho común a todas las partes del mundo, o sufre un proceso de retroceso aún en las zonas marcadas por un constante progreso. Fenómeno este particularmente indicador de la naturaleza del auténtico desarrollo: o participan de él todas las naciones del mundo o no será tal ciertamente"17.

En el momento de la publicación de la Sollicitudo rei socialis se estaba ya alejando la preocupación de los hombres por la posibilidad de una guerra total y habían aparecido claros elementos de distención como fueran los acuerdos sobre la destrucción de armamento nuclear, pero subsistía el espíritu imperialista en las actuaciones políticas que tanto daño habían causado en los pueblos pobres. Para las naciones líderes el objetivo se encontraba constituido por el logro del dominio de un bloque sobre el otro. Por el contrario, para Juan Pablo II lo que debe prevalecer es el deber ético de los poderosos para con los desvalidos. El papa observando el panorama mundial concluye: „Cuando Occidente parece inclinarse a unas formas de aislamiento creciente y egoísta, y Oriente, a su vez, parece ignorar por motivos discutibles su deber de cooperación para aliviar la miseria de los pueblos, uno se encuentra no sólo ante una traición de las legítimas esperanzas de la humanidad con consecuencias imprevisibles, sino ante una defección verdadera y propia respecto de una obligación moral”" ${ }^{\prime 1}$.

Juan Pablo II expone claro de que la Iglesia no se pronuncia a favor de ninguno de los sistemas: „la doctrina social de la Iglesia asume una actitud crítica tanto ante el capitalismo liberal como ante el colectivismo marxista. En efecto, desde el punto de vista del desarrollo surge espontánea la pregunta: ¿de qué manera o en qué medida estos dos sistemas son susceptibles de transformaciones y capaces

\footnotetext{
${ }^{16}$ Ibídem, 16.

${ }^{17}$ Ibídem, 17.

${ }^{18}$ Ibídem, 23.
} 


\section{The Person and the Challenges \\ 154 Volume 2 (2012) Number 1}

de ponerse al día, de modo que favorezcan o promuevan un desarrollo verdadero e integral del hombre y de los pueblos en la sociedad actual? De hecho, estas transformaciones y puestas al día son urgentes e indispensables para la causa de un desarrollo común a todos” ${ }^{\prime 19}$.

La paz no es solamente la ausencia de guerra, porque el nuevo nombre de la paz es el desarrollo, y, en consecuencia, para conseguirla, los países ricos deben orientar la economía hacia el bien común, no sólo a nivel interno, sin también en el campo de las relaciones internacionales. Se trata de llevar a la práctica el contenido de la palabra solidaridad ${ }^{20}$.

El desarrollo sólo puede ser denominado como tal caundo de él participe la totalidad de la humanidad, ya que en modo alguno puede ser entendido este concepto en el contexto de un ambiente denominado por la explotación de unos hombres sobre otros, unos hombres cuyo principal problema no consiste en vivir, sino en sobrevivir ${ }^{21}$.

\section{Pensamiento de Juan Pablo II sobre el concepto de desarrollo}

El concepto de desarrollo en Juan Pablo II se caracteriza principalmente por la insistencia en una connotación moral del progreso. Dicho concepto se encuentra firmemente ligado al éxito económico que propicia, mediante los avances técnicos, la mayor producción de bienes para la satisfacción de las necesidades humanas ${ }^{22}$. Según el papa, el progreso solamente podrá ser estimado como tal, si lleva implícito como objetivo su aplicación al bien del género humano. Al este tema Juan Pablo II dice: „En efecto, hoy se comprende mejor que la mera acumulación de bienes y servicios, incluso en favor de una mayoría, no basta

\footnotetext{
${ }^{19}$ Ibídem, 21.

${ }^{20}$ Juan Pablo II lo explicará bien cuatro años despús en la encíclica Centesimus annus, donde leemos: „Sin embargo, para lograr esto, el pobre - individuo o nación - necesita que se le ofrezcan condiciones realmente asequibles. Crear tales condiciones es el deber de una concertación mundial para el desarrollo, que implica además el sacrificio de las posiciones ventajosas en ganancias y poder, de las que se benefician las economías más desarrolladas. Esto puede comportar importantes cambios en los estilos de vida consolidados, con el fin de limitar el despilfarro de los recursos ambientales y humanos, permitiendo así a todos los pueblos y hombres de la tierra el poseerlos en medida suficiente. A esto hay que añadir la valoración de los nuevos bienes materiales y espirituales, fruto del trabajo y de la cultura de los pueblos hoy marginados, para obtener así el enriquecimiento humano general de la familia de las naciones”. Juan Pablo II, Encíclica Centesimus annus, 52.

${ }^{21}$ Cfr. M. Castillejo Gorraiz, Comentarios a las enciclicas..., p. 39; R. Gómez Pérez, Introducción a la ética social, Madrid 1989, p 106.
}

${ }^{22}$ Cfr. J. Majka, Wezłowe problemy katolickiej nauki spotecznej, Warszawa 1990, p. 78-89. 
para proporcionar la felicidad humana. $\mathrm{Ni}$, por consiguiente, la disponibilidad de múltiples beneficios reales, aportados en los tiempos recientes por la ciencia y la técnica, incluida la informática, traen consigo la liberación de cualquier forma de esclavitud. Al contrario, la experiencia de los últimos años demuestra que si toda esta considerable masa de recursos y potencialidades, puestas a disposición del hombre, no es regida por un objetivo moral y por una orientación que vaya dirigida al verdadero bien del género humano, se vuelve fácilmente contra él para oprimirlo"23.

El papa polaco subraya que el desarrollo debe cifrarse en la obtención de la auténtica felicidad, que no será tal si se cimenta solamente en el „tener” y no tiene en cuenta lo fundamental del hombre que es el „ser”. El desarrollo que atiende exlusivamente a criterios económicos produce el efecto contrario, ya que los pocos que poseen mucho tienen dificultades para alcanzar su propia realización ${ }^{24}$. La dimensión económica debe estar presente, pero el objetivo moral es indispensable para que se cumplan las condiciones que debe reunir el concepto de desarrllo. Este objetivo moral deviene en una obligación no sólo de cada hombre sino de todos y cada uno en su conjunto para con todos los demás. Juan Pablo II lo dice en las siguientes palabras: „En efecto, la cooperación al desarrollo de todo el hombre y de cada hombre es un deber de todos para con todos y, al mismo tiempo, debe ser común a las cuatro partes del mundo: Este y Oeste, Norte y Sur; o, a los diversos mundos, como suele decirse hoy. De lo contrario, si trata de realizarlo en una sola parte, o en un solo mundo, se hace a expensas de los otros; y allí donde comienza, se hipertrofia y se pervierte al no tener en cuenta a los demás”25.

La dignidad del hombre se concreta en salvaguarda de una serie de derechos que el Sumo Pontífice clasifica en dos tipos: los que se refieren al orden interno de cada nación y los que se incluyen en el orden internacional. Entre los primeros se encuentran los derechos individuales: „el derecho a la vida en todas las fases de la existencia; los derechos de la familia, como comunidad social básica o «célula de la sociedad»; la justicia en las relaciones laborales; los derechos concernientes a la vida de la comunidad política en cuanto tal, así como los basados en la vocación trascendente del ser humano, empezando por el derecho a la libertad de profesar y practicar el propio credo religioso"26. En cambio entre los segundos se encuentran los derechos de carácter colectivo: „en las relaciones entre los Estados o, según el lenguaje corriente, entre los diversos «mundos», es necesario el pleno respeto

\footnotetext{
${ }^{23}$ Sollicitudo rei socialis, 28.

${ }^{24}$ Cfr. M. Castillejo Gorraiz, Comentarios a las encíclicas..., p. 40.

${ }^{25}$ Sollicitudo rei socialis, 32.

${ }^{26}$ Ibídem, 33.
} 
de la identidad de cada pueblo, con sus características históricas y culturales. Es indispensable además, como ya pedía la Encíclica Populorum progressio que se reconozca a cada pueblo igual derecho a «sentarse a la mesa del banquete común», en lugar de yacer a la puerta como Lázaro, mientras «los perros vienen y lamen las llagas» (cfr. Lc 16, 21). Tanto los pueblos como las personas individualmente deben disfrutar de una igualdad fundamental sobre la que se basa, por ejemplo, la Carta de la Organización de las Naciones Unidas: igualdad que es el fundamento del derecho de todos a la participación en el proceso de desarrollo pleno"27.

En la Sollicitudo rei socialis Juan Pablo II hace una reflexión sobre el desarrollo desde la fe y su propia experiencia. En el n. 41 de la encíclica explica: „La doctrina social de la Iglesia no es, pues, una « tercera vía » entre el capitalismo liberal y el colectivismo marxista, y ni siquiera una posible alternativa a otras soluciones menos contrapuestas radicalmente, sino que tiene una categoría propia. No es tampoco una ideología, sino la cuidadosa formulación del resultado de una atenta reflexión sobre las complejas realidades de la vida del hombre en la sociedad y en el contexto internacional, a la luz de la fe y de la tradición eclesial. Su objetivo principal es interpretar esas realidades, examinando su conformidad o diferencia con lo que el Evangelio enseña acerca del hombre y su vocación terrena y, a la vez, trascendente, para orientar en consecuencia la conducta cristiana. Por tanto, no pertenece al ámbito de la ideología, sino al de la teología y especialmente de la teología moral”.

Para conseguir el bien común, los países más ricos tienen la obligación moral de modificar el sistema internacional de comercio, aunque sea a costa de una disminución de sus beneficios, reestructurar el sistema financiero y monetario para ir equilibrando el eudeudamiento de las naciones pobres ${ }^{28}$. Pero los países pobres deben buscar en su propio trabajo el éxito de su desarrollo „sin esperarlo todo de los países más favorecidos y actuando en colaboración con los que se encuentran en la misma situación”29. El nombre de esta forma de actuaciónes el de solidaridad, que, llevada a la dimensión universal, pondrá a todos los pueblos en el camino del auténtico desarrollo.

\footnotetext{
${ }^{27}$ Ibídem.

${ }^{28}$ M. Castillejo Gorraiz, Comentarios a las encíclicas..., p. 44.

${ }^{29}$ Sollicitud rei socialis, 44.
} 


\section{25 ańos después - actualidad del documento papal}

El desarrollo afecta a toda la persona, pero también debe tender a ser un desarrollo solidario para la humanidad. Esta tarea requiere una concepción de la economía que garantice, a nivel internacional, la distribución equitativa de los recursos y responda a la interdependencia - económica, política y cultural - que ya une definitivamente a los pueblos entre sí y les hace sentirse vinculados a un único destino. Se da cada vez con mayor amplitud la exigencia de modelos de desarrollo que no prevean sólo elevar a todos los pueblos al nivel del que gozan hoy los países más ricos, sino de fundar sobre el trabajo solidario una vida más digna, hacer crecer efectivamente la dignidad y la creatividad de toda persona y su capacidad de responder a la llamada de Dios. La necesidad de un desarrollo solidario exige una dimensión planetaria en cuanto al modo de afrontar los problemas del mundo, sobre todo económicos. Esto afecta al papel de los Estados y también afecta a los mismos países ricos. Y sobre todo es fundamental una gran obra educativa y cultural ante el rápido desarrollo del progreso técnicoeconómico y la mutación, igualmente rápida, de los procesos de producción y de consumo ${ }^{30}$.

Hablando hoy sobre el desarroll hay que tener en cuenta el concepto de la globalización. La globalización es sinónimo de creciente aceleración e interdependencia global. La globalización es, dicho de una manera simple e introductoria, la compresión del mundo en un lugar unificado. Los pueblos se sienten cada vez más interdependientes y todos sin excepción están implicados en los mismos acontecimientos. El destino de la humanidad se juega en círculos cada vez más cerrados: la prosperidad y el progreso de cada país son, en parte, efecto, y en parte, causa de la prosperidad y del progreso de los demás pueblos. La ambivalencia de la globalización económica es manifiesta. Es un proceso que produce efectos contradictorios, que tiene sus ventajas y desventajas, sus pros y sus contras. Hay pueblos que entran en este proceso y cada vez se enriquecen más y los hay que quedan excluidos, y cada vez son más pobres. Para unos es un fenómeno positivo y para otros un hecho negativo ${ }^{31}$. La encíclica de Benedicto XVI Caritas in veritate nos llama a un discernimiento ponderado y a no dejarse llevar por actitudes fatalistas o producto de fuerzas anónimas e impersonales: "La globalización ha de entenderse ciertamente como un proceso socioeconómico,

\footnotetext{
${ }^{30}$ Cfr. R. Kantor, Prawo do pracy i jej godność wencyklikach , Laborem exercens " $i$,, Centesimus annus” Jana Pawła II, „Praca socjalna” XXIV (2009), n. 1, p. 113-125.

${ }^{31} \mathrm{~J}$. Bestard Comas, El fenómeno de la globalización: una reflexión introductoria, „Revista de Fomento Social” 57 (2002), p. 338.
} 
pero no es ésta su única dimensión. Tras este proceso más visible hay realmente una humanidad cada vez más interrelacionada; hay personas y pueblos para los que el proceso debe ser de utilidad y desarrollo (...) La verdad de la globalización como proceso y su criterio ético fundamental vienen dados por la unidad de la familia humana y su crecimiento en el bien" ${ }^{\text {"32. }}$

Hoy en el siglo XXI observamos síntomas de un desarrollo que produce pobreza. Se constatan aspectos más lacerantes como:

- "el escándalo de las disparidades hirientes";

- corrupción e ilegalidad tanto en el comportamiento de sujetos económicos y políticos de los países ricos, nuevos y antiguos, como en los países pobres;

- falta de respeto de los derechos humanos de los trabajadores provocada a veces por grandes empresas multinacionales y también por grupos de producción local;

- las ayudas internacionales se han desviado con frecuencia de su finalidad por irresponsabilidades tanto en los donantes como en los beneficiarios;

- hay formas excesivas de protección de los conocimientos por parte de los países ricos, a través de un empleo demasiado rígido del derecho a la propiedad intelectual, especialmente en el campo sanitario;

- en algunos países pobres perduran modelos culturales y normas sociales de comportamiento que frenan el proceso de desarrollo;

- el hambre. Eliminarlo en el mundo se ha convertido en una meta que se ha de lograr para salvaguardar la paz y la estabilidad del planeta. El hambre no depende tanto de la escasez material, cuanto de la insuficiencia de recursos sociales, el más importante de los cuales es de tipo institucional ${ }^{33}$. Esta situación exige nuevos esfuerzos de comprensión unitaria y una nueva síntesis humanista para orientar adecuadamente el desarrollo, especialmente los países pobres que tienen en la economía global su gran oportunidad, pero también un ámbito de peligrosos competidores ${ }^{34}$.

La actividad económica no puede resolver todos los problemas sociales ampliando sin más la lógica mercantil. Debe estar ordenada a la consecución del bien común, que es responsabilidad sobre todo de la comunidad política. Por tanto, se debe tener presente que separar la gestión económica, a la que correspondería únicamente producir riqueza, de la acción política, que tendría

${ }^{32}$ Benedicto XVI, Encíclica Caritas in veritate, 42.

${ }^{33}$ Cfr. J. Skwara, Nauczanie społeczne Kościoła, Warszawa 1984, p. 273.

${ }^{34}$ Cfr. F. Fuentes Alcántara, Economía y doctrina scial de la Iglesia, Ponencia para el Curso Taller organizado por el CELAM, la Fundación Konrad Adenauer, ODUCAL y la Fundación Pablo VI, Madrid 2011, p. 8-9. 
el papel de conseguir la justicia mediante la redistribución, es causa de graves desequilibrios ${ }^{35}$.

La doctrina social de la Iglesia sostiene que la actividad económica no debe considerarse antisocial. El mercado no es ni debe convertirse en el ámbito donde el más fuerte avasalle al más débil. „La doctrina social de la Iglesia sostiene que se pueden vivir relaciones auténticamente humanas, de amistad y de sociabilidad, de solidaridad y de reciprocidad, también dentro de la actividad económica y no solamente fuera o después de ella. El sector económico no es ni éticamente neutro ni inhumano o antisocial por naturaleza. Es una actividad del hombre $\mathrm{y}$, precisamente porque es humana, debe ser articulada e institucionalizada éticamente. En las relaciones mercantiles el principio de gratuidad y la lógica del don, como expresiones de fraternidad, pueden y deben tener espacio en la actividad económica ordinaria. Esto es una exigencia del hombre en el momento actual, pero también de la razón económica misma. Una exigencia de la caridad y de la verdad al mismo tiempo" 36 .

Para valorar lo que significa el desarrollo hoy como vocación debemos acudir al texto de la encíclica Caritas in veritate, la cual identifica la aspiración al desarrollo humano como una „vocación” constitutiva del ser humano: „En los designios de Dios, cada hombre está llamado a promover su propio progreso, porque la vida de todo hombre es una vocación. Si éste afecta se sólo a los aspectos técnicos de la vida del hombre, y no al sentido de su caminar en la historia junto con sus otros hermanos, ni al descubrimiento de la meta de este camino, la Iglesia no tendría por qué hablar de él ${ }^{37 ”}$. Decir que el desarrollo es vocación equivale a reconocer: que nace de una llamada trascendente (es incapaz de darse su significado último por sí mismo); utiliza los recursos técnicos y científicos; aborda y se ocupa del sentido del "caminar" del ser humano en la historia junto con sus otros hermanos. "La vocación es una llamada que requiere una respuesta libre y responsable. El desarrollo humano integral supone la libertad responsable de la persona y los pueblos: ninguna estructura puede garantizar dicho desarrollo desde fuera y por encima de la responsabilidad humana. Los mesianismos prometedores, pero forjados de ilusiones basan siempre sus propias propuestas en la negación de la dimensión trascendente del desarrollo, seguros de tenerlo todo a su disposición. Esta falsa seguridad se convierte en debilidad, porque comporta el sometimiento del hombre, reducido a un medio para el desarrollo, mientras que la humildad de

\footnotetext{
${ }^{35}$ Cfr. Caritas in veritate, 36.

${ }^{36}$ Ibídem.

${ }^{37}$ Ibídem, 16.
} 
quien acoge una vocación se transforma en verdadera autonomía, porque hace libre a la persona" 38 .

Es muy relevante la importancia que tiene la libertad humana como la verdadera artífice del desarrollo. Considerar este aspecto significa hacer un discernimiento de la situación del hambre en el mundo; considerar el valor y el papel de las instituciones humanas y los programas técnicos y demás aspectos que deben mover nuestra reflexión. "Esta libertad se refiere al desarrollo que tenemos ante nosotros pero, al mismo tiempo, también a las situaciones de subdesarrollo, que no son fruto de la casualidad o de una necesidad histórica, sino que dependen de la responsabilidad humana. Por eso, los pueblos hambrientos interpelan hoy, con acento dramático, a los pueblos opulentos. También esto es vocación, en cuanto llamada de hombres libres a hombres libres para asumir una responsabilidad común. Pablo VI percibía netamente la importancia de las estructuras económicas y de las instituciones, pero se daba cuenta con igual claridad de que la naturaleza de éstas era ser instrumentos de la libertad humana. Sólo si es libre, el desarrollo puede ser integralmente humano; sólo en un régimen de libertad responsable puede crecer de manera adecuada" 39 .

El verdadero desarrollo, el desarrollo integral es el que respeta todas las exigencias propias del ser humano y de todos los hombres - sea cual fuere su condición física (edad, sexo, salud, enfermedad, etc.), material (riqueza o pobreza) y social ${ }^{40}$.

\section{Conclusión}

El diagnóstico de la situación que hace Juan Pablo II es bastante más negativo que el de Populorum progressio, cosa bien explicable a tenor de lo ocurrido en estos 20 años. Es un diagnóstico que se ensombrece aún más cuando se subraya que el tercer mundo ha perdido ya la esperanza. El atraso no es sólo económico, sino también cultural, político y humano . En la enumeración de diferentes manifestaciones de este balance tan pesimista hay un pasaje que alude inequívocamente a los países colectivistas, una preocupación que Juan Pablo II llevó muy en el corazón durante todo su pontificado. Sin que haya una mención expresa a estos países de los que el papa provenía, en el pasaje mencionado se denuncia la negación del derecho de iniciativa económica y de la verdadera

\footnotetext{
${ }^{38}$ Ibídem, 17.

${ }^{39}$ Ibídem.

${ }^{40}$ Cfr. Sollicitudo rei socialis, 33.
} 
soberanía de las naciones, así como la pretensión de un partido de convertirse en el único guía de la sociedad.

Juan Pablo II subraya carácter ético del desarrollo. El desarrollo no es una cuestión exclusivamente técnica, sino esencialmente ética. Esto significa que necesita apoyarse en ciertas opciones, porque no es el resultado de un "ingenuo optimismo mecanicista”. Tampoco cabe reducirlo a mera acumulación de bienes y servicios, ni a una dinámica de crecimiento que hace al ser humano esclavo de la posesión. La técnica exige ser puesta al servicio de decisiones morales. Es en este ámbito donde la Iglesia tiene una palabra que decir, para contribuir a que el desarrollo sea "conforme a la dignidad del hombre y de los pueblos".

Aunque los tiempos avanzan a un ritmo nunca antes alcanzado, el pensamiento de la encíclica, lejos de perder actualidad, la tiene hoy de forma renovada si la vemos como una reflexión dinámica y abierta a este mundo cambiante. El Programa de Naciones Unidas para el Desarrollo ha querido salir al paso de una concepción demasiado economicista del desarrollo. Y lo ha hecho acercándose y dando contenidos más concretos a ese desarrollo integral que la Iglesia elaboró sobre todo en la encíclica Sollicitudo rei socialis. He aquí las formulaciones iniciales del concepto: "Proceso de ampliar la gama de opciones de las personas, brindándoles mayores oportunidades de educación, atención médica, ingreso y empleo, y abarcando el espectro total de opciones humanas, desde un entorno físico en buenas condiciones hasta libertades económicas y políticas”41. Este concepto ha sido de gran utilidad para reorientar las políticas de ayuda de los organismos internacionales y de los gobiernos desarrollados. Además ha sido reelaborado ulteriormente añadiéndole los conceptos de libertad humana, seguridad humana o capacidades humanas, que explicitan algunas dimensiones de un auténtico desarrollo.

${ }^{41}$ Programa de las Naciones Unidas para el desarrollo, Informe sobre desarrollo humano, Nueva York1992, p. 18. 


\section{Bibliography}

Benedicto XVI, Encíclica Caritas in veritate.

Benedicto XVI, Encíclica Spe salvi.

Bestard Comas J., El fenómeno de la globalización: una reflexión introductoria, „Revista de Fomento Social” 57 (2002), p. 335-343.

Castillejo Gorraiz M., Comentarios a las encíclicas sociales de Juan Pablo II, Córdoba 1995.

Gómez Pérez R., Introducción a la ética social, Madrid 1989.

Juan Pablo II, Encíclica Sollicitudo rei socialis.

Kantor R., Prawo do pracy i jej godność w encyklikach „Laborem exercens” $i$,, Centesimus annus” Jana Pawła II, „Praca socjalna” XXIV (2009), n. 1, p. 113-125.

Majka J., Węzłowe problemy katolickiej nauki społecznej, Warszawa 1990.

Pablo VI, Encíclica Populorum progressio.

Skwara J., Nauczanie społeczne Kościoła, Warszawa 1984. 